\title{
Correlations of Fresh Sperm Quality and Kinematic Attributes to Those of Post-Thawed Sperms of Bulls Assessed by CASA
}

\author{
P.K. Pathak, A.J. Dhami* and D.V. Chaudhari \\ Department of Veterinary Gynaecology \& Obstetrics, College of Veterinary Science \& Animal \\ Husbandry, Anand Agricultural University, Anand-388 001, Gujarat, India \\ *Corresponding author
}

\begin{tabular}{|l|}
\hline K e y w o r d s \\
$\begin{array}{l}\text { Bovine, CASA, } \\
\text { Correlations, Fresh } \\
\text { semen, Frozen-thawed } \\
\text { semen, Subjective } \\
\text { evaluation }\end{array}$ \\
\hline Article Info \\
\hline $\begin{array}{l}\text { Accepted: } \\
\text { 18 August } 2018 \\
\text { Available Online: } \\
\text { 10 September } 2018\end{array}$ \\
\hline
\end{tabular}

\section{Introduction}

In bovine reproduction, fertility of male is an important factor since a single bull is generally bred to thousands of cows through AI. Semen analysis is commonly used to evaluate male fertility potential (Verstegen $e t$ al., 2002; Rana and Dhami, 2003; Patel and
Dhami, 2013). However, no single test or combinations of tests have been proved to be totally reliable for accurate prediction of semen quality in relation to fertility. The correlations of the physical characters with fertility are highly variable and relatively poor (Shelke and Dhami, 2001; Tiwari et al., 2009; Chaudhary et al., 2017). There are numerous 
factors including dilutor and freezing-thawing protocol that may affect the motility, plasma membrane integrity, morphology and viability of fresh and frozen-thawed semen. Recently more attention has been given to evaluating sperm plasma membrane integrity through HOS test (Jayendran et al., 1984; Lodhi et al., 2008) and motion characteristics using computer assisted semen analyzer-CASA (Budworth et al., 1988; Amann and Waberski, 2014), since subjective evaluation of sperm quality is highly inconsistent.

The literature on use of CASA in bovine semen laboratory, and the interrelationships of spermatozoal attributes of fresh semen to those of cryopreserved bovine semen assessed subjectively and objectively by CASA is however meager (Anderson et al., 1992; Mandal et al., 2003; Rana and Dhami, 2003; Chaudhary et al., 2014; Patel and Dhami, 2013 \& 2016). Such correlations if established would help to select a few most valid simple traits of fresh semen to predict freezability/post-thaw quality and thereby fertility of such ejaculates. Hence, this study was planned to evaluate the interrelationships of spermatozoal attributes of fresh semen to those of frozen-thawed semen of cattle and buffalo bulls assessed subjectively and objectively by CASA.

\section{Materials and Methods}

This study was carried out on semen of nine healthy mature breeding bulls ( 3 each of Gir, Surti and Murrah breed), aged 5-8 years, at the College of Veterinary Science, AAU, Anand388001 during the favourable season (winter) of year 2017-18. All these bulls were in good health and under optimal veterinary care. They were maintained in nearly identical nutritional and managerial conditions throughout the period of study with twice a week semen collection schedule. Semen was collected using artificial vagina from each bull in the morning hours between 7.30 and 8.30 am over a dummy buffalo bull. Ejaculates collected at weekly interval were used for this study. Immediately after collection, the ejaculates $(n=72)$ with $>75 \%$ initial motility were evaluated for various seminal attributes, and soon extended at $34^{\circ} \mathrm{C}$ with Tris-citric acidfructose-egg yolk-glycerol (TFYG) extender keeping 80 million sperm per $\mathrm{ml}$. The extended semen was assessed for sperm motility, morphology and viability including hypo-osmotic swelling (HOS) test (Jayendran et al., 1984) subjectively, and sperm motion characteristics by Biovis CASA.

The extended semen was soon filled and sealed in French mini straws by IS4 machine (IMV, France), cooled to $5^{\circ} \mathrm{C}$, equilibrated for $4 \mathrm{hrs}$ and frozen in liquid nitrogen vapour using a bio-freezer (IMV, France) employing standard freezing protocol. The straws were thawed in water bath at $37^{\circ} \mathrm{C}$ for $30 \mathrm{sec}$, and were again assessed for sperm motility, viability, morphology, HOS test and sperm motion characteristics by CASA. The CASA traits studied included total motile sperm, rapid and slow progressive motile sperm, immotile sperm, average path velocity (VAP), curvilinear velocity (VCL), straight line velocity (VSL), straightness (STR), linearity (LIN), wobbling (WOB), beat-cross frequency (BCF), amplitude of lateral head displacement (ALH), dancing velocity (DNC) and dancing mean (DNM). The data so generated on sperm quality traits of fresh and frozen-thawed semen were analyzed statistically and the correlations of spermatozoal attributes of fresh semen to those of frozen-thawed semen were worked out using standard statistical package on SPSS software version 20.00 for each breed (Snedecor and Cochran, 1994).

\section{Results and Discussion}

The correlations of fresh sperm quality and velocity/kinematic parameters of 
progressively motile sperms to those of postthawed semen assessed subjectively and by Biovis CASA for bulls of Gir, Surti and Murrah breeds are presented in Table 1 to 3, respectively.

\section{Correlations of fresh with frozen-thawed sperm traits in Gir bulls}

The sperm motility, live sperm, abnormal sperm, rapid progressive motile sperm, VAP, VSL and STR of fresh Gir bull sperm had no significant correlations with any of the attributes of its post-thawed semen (Table 1). However, the initial and post-thawed HOS reactive sperms were highly significantly $(p<0.01)$ and positively correlated (0.62). The total motile sperms of fresh semen had significant $(\mathrm{p}<0.05)$ positive correlation with post-thawed slow progressive sperm (0.51). The slow progressive sperms in fresh semen had significant $(\mathrm{p}<0.05)$ positive correlations with post-thawed HOST (0.44) and STR (0.45), and negative correlations with postthawed ALH, DNC, DNM (-0.49, -0.47, $0.50)$.

The VCL of fresh sperm showed significant $(\mathrm{p}<0.05)$ positive correlations with postthawed live sperm (0.43), ALH (0.52), DNC (0.51) and DNM (0.53). The LIN of fresh sperm had significant $(\mathrm{p}<0.05)$ positive correlation with post-thawed slow progressive sperm (0.48) and negative correlations with post-thawed VCL, VAP, DNC (-0.50, -0.41, 0.45). The WOB per cent in fresh semen revealed significant $(\mathrm{p}<0.05)$ positive correlation with post-thawed slow progressive sperm (0.48) and negative correlations with post-thawed VCL, VAP, BCF, DNC (-0.51, $0.44,-0.43,-0.44)$. The BCF of fresh sperm had significant $(\mathrm{p}<0.01)$ positive correlations with post-thawed live sperm, ALH, DNC, DNM $(0.51,0.68,0.62,0.63)$ and negative correlations with slow progressive sperms and STR $(-0.43,-0.47)$.
The ALH of fresh sperm was significantly $(\mathrm{p}<0.01)$ and positively correlated with postthawed VCL, BCF, ALH, DNC, DNM (0.50, $0.41,0.68,0.62,0.63)$, and negatively with slow progressive sperm (-0.54). The DNC of fresh sperm had significant $(\mathrm{p}<0.01)$ positive correlations with post-thawed VCL, ALH, DNC, DNM (0.49, 0.64, 0.66, 0.65), and negative correlation with slow progressive motile sperm (-0.56). The DNM of fresh sperm showed significant $(\mathrm{p}<0.01)$ positive correlations with post-thawed VCL, ALH, BCF, DNC, DNM (0.53, 0.55, 0.43, 0.57, $0.53)$, and negative correlation with slow progressive motile sperm (-0.55).

In the literature reviewed, very few studies showed evaluation of the interrelationship of fresh and frozen-thawed sperm quality assessed subjectively and/or objectively by CASA. Anderson et al., (1992) found significant correlation for post-thaw motility of bulls assessed by subjective means and by CASA, but not between post-thaw motility and non-return rates. Ferrell et al., (1998) observed bull fertility to be positively correlated with motile spermatozoa, progressive motility, critical velocity (VCL), average path velocity (VAP) and straight line velocity (VSL) values. Kathiravan et al., (2008) studied the effective relationship between different motion characteristics of bull spermatozoa assessed by computer assisted semen analyzer (CASA) and in vitro fertilization percentage in Zona-free hamster oocytes. Among different CASA variables, progressive motility alone contributed to 62.60 per cent variation in the fertilization percentage. The velocity measurements (VAP and VSL) together with progressive motility and HOS spermatozoa contributed to 66.10 per cent of variation $(p<0.05)$ in fertilization percentage. Our correlation findings for CASA traits were also in accordance with Patel and Dhami (2013) in fresh and frozenthawed semen of crossbred bulls. 
Correlations of fresh with frozen-thawed sperm traits in Surti bulls

The initial motility, abnormal sperm, rapid progressive motile sperm, VAP and VSL of fresh sperms of Surti bulls had no significant correlations with any of the attributes of postthawed semen, except subjective motility with post-thawed total motile sperms by CASA (0.52) (Table 2).

The HOS reactive sperm in fresh semen had significant $(\mathrm{p}<0.05)$ positive correlations with post-thawed motility, HOS reactive sperm and live sperm $(0.40,0.69,0.49)$ and LIN $(0.42)$, and negative correlations with post-thawed abnormal sperm (-0.41), BCF, ALH, DNC and DNM (-0.54, -0.66, -0.62, -0.58).

The percentage of live sperm in fresh semen showed significant $(\mathrm{p}<0.05)$ positive correlations with post-thawed HOS reactive and live sperm $(0.64,0.47)$, total motile sperm (0.41), and negative correlations with postthawed abnormal sperm $(-0.53)$, BCF, ALH, DNC, DNM (-0.48, $-0.56,-0.48,-0.44)$. The percentage of total motile sperm in fresh semen revealed significant $(\mathrm{p}<0.05)$ positive correlations with post-thawed total motile sperm (0.48), STR (0.44), and negative correlations with ALH and DNM (-0.42, $0.41)$.

The percentage of slow progressive sperm in fresh semen had significant $(\mathrm{p}<0.05)$ positive correlation with post-thawed slow progressive sperm (0.51) and negative correlations with ALH, DNC and DNM (-0.40, -0.42, -0.42).

The VCL of fresh sperms had significant $(\mathrm{p}<0.05)$ positive correlations with postthawed VCL, ALH, DNC, DNM (0.44, 0.48, $0.52,0.54)$, and negative correlations with post-thawed HOST (-0.41), abnormal sperm ($0.53)$ and LIN (-0.43). The LIN of fresh sperms was significantly $(\mathrm{p}<0.05)$ and positively correlated with post-thawed HOST, abnormal sperm, LIN, WOB (0.62, 0.42, 0.47, 0.47 ) and negatively with live sperm, total motile sperm $(-0.54,-0.64)$, VCL, BCF, ALH, DNC and DNM $(-0.42,-0.47,-0.54,-0.55$, $0.52)$.

The STR of fresh sperms showed significant $(p<0.05)$ negative correlations with post-thaw motility, VCL, DNM $(-0.44,-0.48,-0.44)$ as well as live sperm, total motile sperm, BCF, ALH, DNC (-0.56, -0.48, -0.62, -0.52, -0.60), and positive correlation with post-thawed HOST (0.70). The WOB per cent of fresh sperm had significant $(\mathrm{p}<0.05)$ positive correlations with post-thawed HOST, abnormal sperm, LIN, WOB $(0.55,0.41,0.48$, 0.46 ) and negative correlations with postthawed total motile sperm, live sperm, ALH, DNC, DNM (-0.62, -0.50, -0.50, -0.51, -0.51). The BCF of fresh sperm had significant $(p<0.05)$ positive correlations with postthawed ALH, DNC, DNM (0.51, 0.41, 0.61) and negative correlations with post-thawed HOST, abnormal sperm, LIN, STR and WOB $(-0.43,-0.58,-0.58,-0.54,-0.50)$.

The ALH of fresh sperm revealed significant $(\mathrm{p}<0.05)$ positive correlations with postthawed ALH, DNM, DNC $(0.55,0.58,0.52)$ and negative correlations with HOST, STR, LIN, WOB (-0.51, $-0.41,-0.58,-0.54)$.

The DNC of fresh sperm had significant $(\mathrm{p}<0.05)$ positive correlations with postthawed live sperm (0.47), VCL, ALH, DNC, DNM $(0.47,0.65,0.66,0.69)$ and negative correlations with post-thawed HOST, abnormal sperm, STR, LIN, WOB (-0.60, $0.55,-0.46,-0.63,-0.58)$, while DNM of fresh sperm showed significant $(\mathrm{p}<0.05)$ positive correlations with post-thawed live sperm, total motile sperm, VCL, BCF $(0.48,0.48,0.49$, $0.41)$, ALH, DNC, DNM (0.61, 0.63, 0.63), and negative correlations with post-thawed HOST, LIN and WOB (-0.62, $-0.57,-0.53)$. 
Table.1 Interrelationships of sperm quality and kinematics attributes of fresh semen to those of post-thawed semen in Gir bulls assessed by subjective method and Biovis CASA

\begin{tabular}{|c|c|c|c|c|c|c|c|c|c|c|c|c|c|c|c|c|c|c|}
\hline \multicolumn{2}{|c|}{ Sperm Attributes } & \multicolumn{17}{|c|}{ Post-thawed seminal attributes } \\
\hline & & Motility & HOST & $\begin{array}{c}\text { Live } \\
\text { Sp }\end{array}$ & $\begin{array}{c}\text { Abn } \\
\text { Sp }\end{array}$ & $\begin{array}{c}\text { Total } \\
\text { motile }\end{array}$ & $\begin{array}{c}\text { Rapid } \\
\text { prog. }\end{array}$ & $\begin{array}{l}\text { Slow } \\
\text { prog. }\end{array}$ & VCL & VAP & VSL & LIN & STR & WOB & $\mathrm{BCF}$ & ALH & DNC & DNM \\
\hline \multirow{17}{*}{ 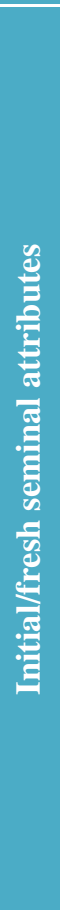 } & Motility & 0.39 & 0.39 & 0.16 & -0.25 & 0.35 & 0.30 & 0.11 & -0.02 & 0.23 & 0.17 & 0.16 & -0.16 & 0.21 & 0.22 & -0.04 & -0.11 & -0.17 \\
\hline & HOST & 0.21 & $0.62^{* *}$ & 0.06 & -0.17 & 0.27 & 0.03 & 0.32 & -0.16 & -0.02 & -0.06 & 0.09 & -0.13 & 0.13 & -0.01 & -0.10 & -0.21 & -0.19 \\
\hline & Live $\mathrm{Sp}$ & 0.07 & 0.33 & 0.00 & -0.09 & 0.18 & 0.07 & 0.08 & -0.05 & 0.14 & 0.10 & 0.18 & -0.07 & 0.18 & 0.01 & -0.23 & -0.22 & -0.25 \\
\hline & Abn Sp & -0.34 & -0.39 & -0.01 & 0.22 & 0.07 & -0.13 & 0.02 & 0.11 & -0.14 & -0.10 & -0.19 & 0.16 & -0.26 & -0.04 & 0.08 & 0.16 & 0.17 \\
\hline & Total mot & -0.36 & 0.29 & -0.32 & 0.28 & 0.12 & -0.16 & $0.51^{*}$ & -0.24 & -0.14 & -0.06 & 0.22 & 0.21 & 0.16 & -0.20 & -0.33 & -0.36 & -0.34 \\
\hline & Rapid prg & 0.01 & -0.11 & 0.21 & -0.09 & 0.19 & -0.07 & 0.28 & -0.17 & -0.27 & -0.33 & -0.20 & -0.26 & -0.10 & -0.10 & 0.14 & 0.05 & 0.16 \\
\hline & Slow prog & -0.30 & $0.44^{*}$ & -0.25 & 0.30 & 0.12 & -0.10 & 0.22 & -0.11 & 0.01 & 0.15 & 0.31 & $0.45^{*}$ & 0.18 & -0.11 & $-0.49^{*}$ & $-0.47^{*}$ & $-0.50^{*}$ \\
\hline & VCL & 0.31 & -0.23 & $0.43^{*}$ & -0.26 & 0.33 & 0.25 & -0.23 & 0.24 & 0.03 & -0.10 & -0.40 & -0.33 & -0.32 & 0.18 & $0.52^{* *}$ & $0.51^{*}$ & $0.53^{* *}$ \\
\hline & VAP & 0.07 & -0.18 & 0.22 & -0.07 & 0.20 & -0.04 & 0.14 & -0.16 & -0.29 & -0.37 & -0.24 & -0.28 & -0.15 & -0.14 & 0.22 & 0.15 & 0.24 \\
\hline & VSL & 0.01 & -0.13 & 0.18 & 0.01 & 0.20 & -0.05 & 0.19 & -0.20 & -0.30 & -0.36 & -0.18 & -0.25 & -0.10 & -0.14 & 0.14 & 0.07 & 0.16 \\
\hline & LIN & -0.28 & 0.05 & -0.30 & 0.26 & -0.14 & -0.35 & $0.48^{*}$ & $-0.50^{*}$ & $-0.41^{*}$ & -0.34 & 0.19 & 0.04 & 0.22 & -0.38 & -0.39 & $-0.45^{*}$ & -0.38 \\
\hline & STR & -0.28 & 0.11 & -0.02 & 0.40 & 0.05 & -0.12 & 0.35 & -0.28 & -0.19 & -0.14 & 0.17 & 0.03 & 0.19 & -0.06 & -0.30 & -0.34 & -0.32 \\
\hline & WOB & -0.26 & 0.03 & -0.22 & 0.21 & -0.17 & -0.38 & $0.48^{*}$ & $-0.51^{*}$ & $-0.44^{*}$ & -0.38 & 0.17 & 0.04 & 0.21 & $0-.43^{*}$ & -0.38 & $-0.44^{*}$ & -0.36 \\
\hline & $\mathrm{BCF}$ & 0.30 & -0.29 & $0.51^{*}$ & -0.35 & 0.25 & 0.40 & $-0.43^{*}$ & 0.29 & 0.16 & -0.01 & -0.37 & $-0.47^{*}$ & -0.25 & 0.36 & $0.68^{* *}$ & $0.62^{* *}$ & $0.63^{* *}$ \\
\hline & ALH & 0.19 & -0.13 & 0.32 & -0.29 & 0.15 & 0.36 & $-0.54^{* *}$ & $0.50^{*}$ & 0.35 & 0.25 & -0.33 & -0.23 & -0.29 & $0.41^{*}$ & $0.56^{* *}$ & $0.58^{* *}$ & $0.55^{* *}$ \\
\hline & DNC & 0.26 & -0.23 & 0.37 & -0.35 & 0.15 & 0.35 & $-0.56^{* *}$ & $0.49^{*}$ & 0.30 & 0.17 & -0.40 & -0.31 & -0.34 & 0.40 & $0.64^{* *}$ & $0.66^{* *}$ & $0.65^{* *}$ \\
\hline & DNM & 0.21 & -0.14 & 0.28 & -0.28 & 0.14 & 0.38 & $-0.55^{* *}$ & $0.53^{* *}$ & 0.39 & 0.30 & -0.30 & -0.20 & -0.28 & $0.43^{*}$ & $0.55^{* *}$ & $0.57^{* *}$ & $0.53^{* *}$ \\
\hline
\end{tabular}


Table.2 Interrelationships of sperm quality and kinematics attributes of fresh semen to those of post-thawed semen in Surti buffalo bulls assessed by subjective method and Biovis CASA

\begin{tabular}{|c|c|c|c|c|c|c|c|c|c|c|c|c|c|c|c|c|c|c|}
\hline \multirow{2}{*}{\multicolumn{2}{|c|}{$\begin{array}{c}\text { Sperm } \\
\text { Attributes }\end{array}$}} & \multicolumn{17}{|c|}{ Post-thawed seminal attributes } \\
\hline & & Motility & HOST & Live $\mathrm{Sp}$ & Abn $\mathrm{Sp}$ & Total & Rapid & Slow & VCL & VAP & VSL & LIN & STR & WOB & $\mathrm{BCF}$ & ALH & $\mathrm{DNC}$ & DNM \\
\hline \multirow{17}{*}{ 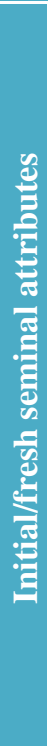 } & Motility & 0.34 & 0.10 & 0.22 & 0.02 & $0.52^{* *}$ & 0.31 & 0.06 & 0.13 & 0.21 & 0.27 & 0.18 & 0.30 & 0.11 & 0.14 & -0.18 & -0.07 & -0.15 \\
\hline & HOST & 0.40 & $0.69^{* *}$ & $0.49^{*}$ & $-0.41^{*}$ & 0.33 & -0.25 & 0.16 & -0.37 & -0.19 & -0.09 & $0.42^{*}$ & 0.39 & 0.34 & $-0.54^{* *}$ & $-0.66^{* *}$ & $-0.62^{* *}$ & $-0.58^{* *}$ \\
\hline & Live $\mathrm{Sp}$ & 0.29 & $0.64^{* *}$ & $0.47^{*}$ & $-0.53^{* *}$ & $0.41^{*}$ & -0.18 & -0.00 & $0-.24$ & -0.12 & -0.04 & 0.32 & 0.37 & 0.25 & $-0.48^{*}$ & $-0.56^{* *}$ & $-0.48^{*}$ & $-0.44^{*}$ \\
\hline & Abn $\mathrm{Sp}$ & -0.05 & -0.22 & -0.08 & -0.06 & 0.09 & 0.30 & -0.11 & 0.08 & 0.32 & 0.28 & 0.12 & -0.14 & 0.19 & 0.30 & 0.12 & 0.09 & -0.06 \\
\hline & Total mot & -0.02 & 0.28 & -0.11 & 0.25 & $0.48^{*}$ & 0.30 & 0.20 & -0.05 & 0.10 & 0.19 & 0.37 & $0.44^{*}$ & 0.29 & -0.07 & $-0.42^{*}$ & -0.31 & $-0.41^{*}$ \\
\hline & Rapid prg & -0.01 & 0.08 & -0.06 & -0.07 & -0.12 & 0.10 & -0.30 & 0.11 & 0.04 & 0.03 & -0.07 & -0.05 & -0.06 & -0.09 & 0.01 & 0.04 & 0.11 \\
\hline & Slow prog & -0.06 & 0.26 & -0.09 & 0.32 & 0.08 & -0.11 & $0.51^{*}$ & -0.34 & -0.20 & -0.11 & 0.26 & 0.34 & 0.19 & -0.19 & -0.40 & $-0.42^{*}$ & $-0.42^{*}$ \\
\hline & VCL & 0.25 & $-0.41^{*}$ & 0.38 & $-0.53^{* *}$ & 0.34 & 0.13 & -0.36 & $0.44^{*}$ & 0.14 & 0.05 & $-0.43^{*}$ & -0.35 & -0.38 & 0.30 & $0.48^{*}$ & $0.52^{* *}$ & $0.54^{* *}$ \\
\hline & VAP & 0.03 & -0.04 & 0.03 & -0.27 & -0.08 & 0.07 & -0.36 & 0.17 & 0.12 & 0.07 & -0.12 & -0.17 & -0.09 & 0.03 & 0.16 & 0.19 & 0.22 \\
\hline & VSL & -0.06 & 0.10 & -0.08 & -0.17 & -0.18 & 0.02 & -0.34 & 0.09 & 0.07 & 0.03 & -0.05 & -0.15 & -0.01 & -0.08 & 0.05 & 0.06 & 0.11 \\
\hline & LIN & -0.39 & $0.62^{* * *}$ & $-0.54^{* *}$ & $0.42^{*}$ & $-0.64^{* *}$ & -0.13 & -0.05 & $-0.42^{*}$ & -0.05 & 0.01 & $0.47^{*}$ & 0.26 & $0.47^{*}$ & $-0.47^{*}$ & $-0.54^{* *}$ & $-0.55^{* *}$ & $-0.52^{* *}$ \\
\hline & STR & $-0.44^{*}$ & $0.70^{* *}$ & $-0.56^{* *}$ & 0.35 & $-0.55^{* *}$ & -0.28 & 0.02 & $-0.48^{*}$ & -0.26 & -0.25 & 0.30 & 0.01 & 0.33 & $-0.62^{* *}$ & $-0.52^{* *}$ & $-0.60^{* *}$ & $-0.44^{*}$ \\
\hline & WOB & -0.35 & $0.55^{* *}$ & $-0.50^{*}$ & $0.41^{*}$ & $-0.62^{* *}$ & -0.08 & -0.05 & -0.39 & -0.00 & 0.07 & $0.48^{*}$ & 0.30 & $0.46^{*}$ & -0.40 & $-0.50^{*}$ & $-0.51^{*}$ & $-0.51^{*}$ \\
\hline & $\mathrm{BCF}$ & 0.25 & $-0.43^{*}$ & 0.39 & $-0.58^{* *}$ & 0.20 & -0.14 & -0.07 & 0.19 & -0.22 & -0.33 & $-0.58^{* *}$ & $-0.54^{* *}$ & $-0.50^{*}$ & 0.04 & $0.51^{*}$ & $0.41^{*}$ & $0.61^{* *}$ \\
\hline & ALH & 0.17 & $-0.51^{*}$ & 0.37 & -0.39 & 0.29 & -0.05 & 0.08 & 0.35 & -0.09 & -0.18 & $-0.58^{* *}$ & $-0.41^{*}$ & $-0.54^{* *}$ & 0.25 & $0.55^{* *}$ & $0.52^{*}$ & $0.58^{* *}$ \\
\hline & DNC & 0.27 & $-0.60^{* *}$ & $0.46^{*}$ & $-0.55^{* *}$ & 0.40 & 0.02 & -0.10 & $0.47^{*}$ & 0.00 & -0.10 & $-0.63^{* *}$ & $-0.46^{*}$ & $-0.58^{* *}$ & 0.33 & $0.65^{* *}$ & $0.66^{* *}$ & $0.69^{* *}$ \\
\hline & DNM & 0.28 & $-0.62^{* *}$ & $0.48^{*}$ & $-045^{*}$ & $0.48^{*}$ & 0.05 & -0.03 & $0.49^{*}$ & 0.05 & -0.04 & $-0.57^{* *}$ & -0.39 & $-0.53^{* *}$ & $0.41^{*}$ & $0.61^{\text {** }}$ & $0.63^{* *}$ & $0.63^{* *}$ \\
\hline
\end{tabular}


Table.3 Interrelationships of sperm quality and kinematics attributes of fresh semen to those of post-thawed semen in Murrah buffalo bulls assessed by subjective method and Biovis CASA

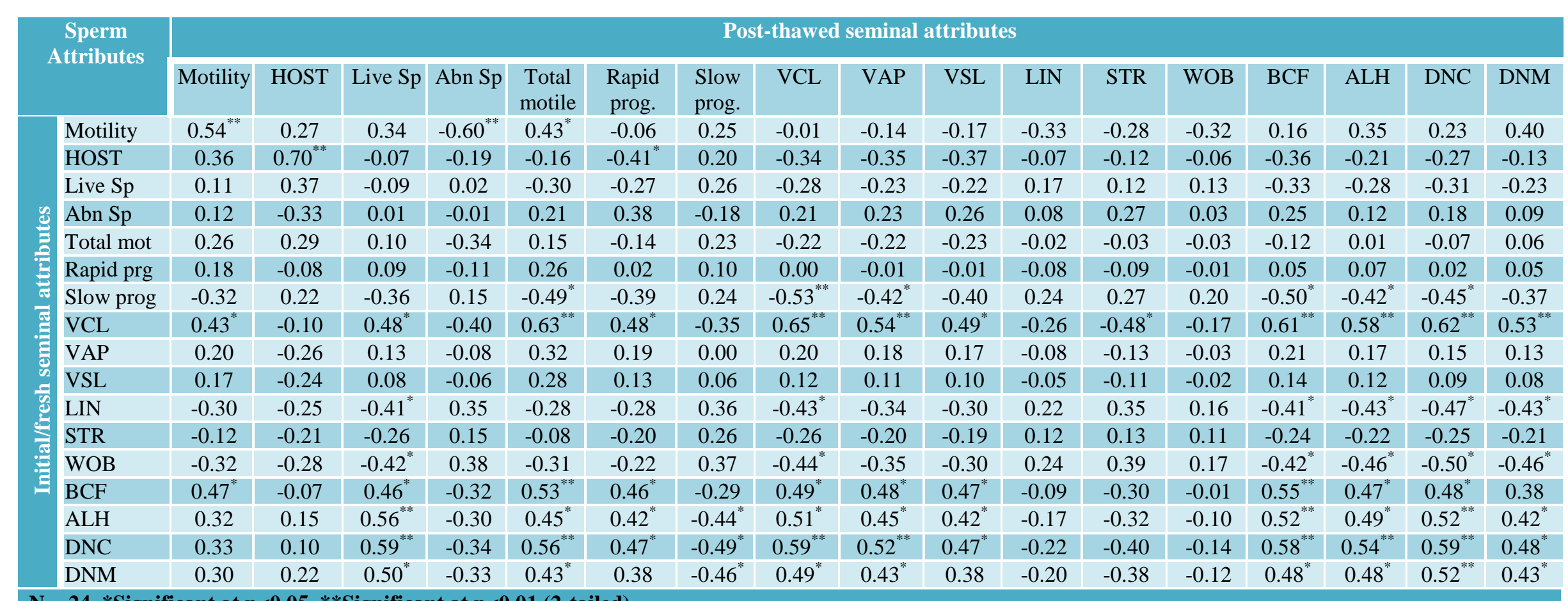

$\mathbf{N}=24$, *Significant at $\mathbf{p}<0.05$, **Significant at $\mathbf{p}<0.01$ (2-tailed). 
Correlations of fresh with frozen-thawed sperm traits in Murrah bulls

The fresh seminal attributes of Murrah buffalo bulls like, live sperm, abnormal sperm, total motile sperm, rapid progressive sperm, VAP, VSL, STR had no significant correlations with any of the post-thawed seminal attributes (Table 3). Among the significant $(p<0.05)$ correlations, the sperm motility of fresh semen was positively correlated with post-thawed motility (0.54), total motile sperm (0.43) and negatively with post-thawed abnormal sperm $(-0.60)$. The HOS reactive sperm of fresh semen had positive correlation only with post-thawed HOS reactive test $(0.070)$ and negative correlation with post-thawed progressive motile sperm (-0.41). The slow progressive motile sperm in fresh semen had significant $(\mathrm{p}<0.05)$ negative correlations with postthawed total motile sperms, VCL, VAP, BCF, ALH, DNC (-0.49, -0.53, -0.42, -0.50, -0.42, $0.45,-0.37)$.

The VCL of fresh sperm revealed significant $(\mathrm{p}<0.05)$ positive correlations with postthawed motility, live sperm, rapid progressive sperm, VSL $(0.43,0.48,0.48,0.49)$, highly significant $(\mathrm{p}<0.01)$ positive correlations with post-thawed total motile sperm, VCL, VAP, BCF, ALH, DNC, DNM (0.63, 0.65, 0.54, $0.61, \quad 0.58, \quad 0.62,0.53)$ and negative correlation only with post-thawed STR ($0.48)$. The LIN and WOB in fresh semen had significant $(\mathrm{p}<0.05)$ negative correlations with post-thawed live sperm, VCL, BCF, ALH, DNC, DNM $(-0.41,-0.43,-0.41,-0.43,-0.47$, -0.43 ; and $-0.42,-0.44,-0.42,-0.46,-0.50$, 0.46 ), while the BCF of fresh sperm revealed significant $(\mathrm{p}<0.05)$ positive correlations with post-thawed motility, total motile sperm, live sperm, rapid progressive motile sperm ( 0.47 , $0.63,0.46,0.46)$, VCL, VAP, VSL, ALH, $\mathrm{BCF}$ and DNC $(0.49,0.48,0.47,0.47,0.55$, $0.48)$.
The ALH of fresh sperm showed highly significant $(p<0.01)$ positive correlations with post-thawed live sperm, BCF, DNC $(0.56$, $0.52,0.52)$, significant $(\mathrm{p}<0.05)$ positive correlations with post thawed total motile sperm, rapid progressive sperm, VCL, VAP, VSL, ALH, DNM $(0.45,0.42,0.51,0.45$, $0.42,0.49,0.42)$, and negative correlation with slow progressive motile sperm (-0.44). The DNC of fresh sperm had highly significant $(p<0.01)$ positive correlations with post-thawed live sperm, total motile sperms, VCL, VAP, BCF, ALH, DNC (0.59, 0.56, $0.59, \quad 0.52, \quad 0.58,0.54,0.59)$, significant $(\mathrm{p}<0.05)$ positive correlations with postthawed rapid progressive motile, VSL, DNM $(0.47,0.47,0.48)$ and negative correlation with slow progressive motile sperm (-0.49), while the DNM of fresh sperm revealed significant $(p<0.05)$ positive correlations with post-thawed live sperm, total motile sperm, VCL, VAP, BCF, ALH, DNM and DNC $(0.50,0.43,0.49,0.43,0.48,0.48,0.43,0.52)$ and negative correlation with slow progressive motile sperm $(-0.46)$.

Mandal et al., (2003) evaluated Murrah buffalo semen for routine parameters, motion characteristics, morphological abnormalities and HOS test, and reported that sperm kinematics had significant $(\mathrm{p}<0.01)$ positive correlations $(\mathrm{r}=0.25$ to 0.60$)$ with plasmallemal integrity. Patel and Dhami (2016) reported significant correlations of initial motility and live sperm assessed subjectively with CASA traits of fresh and frozen-thawed semen of Jafarabadi and Mehsana buffalo bulls, and all the sperm motility and velocity traits of fresh and frozen-thawed semen assessed by CASA were significantly interrelated among both the breeds. The present correlations to the greatest extent were in line with these reports of motion and kinematics attributes of fresh and frozen semen assessed by CASA. Anand and Yadav (2016) reported the motion and 
kinematics characteristics of frozen-thawed sperms of Sirohi goat, while Kumar et al., (2018) evaluated the motion and kinematics of pre-freeze and post-thawed buffalo semen using CASA. Significantly $(p<0.01)$ higher value of live sperm per cent, HOS reactive sperm, and acrosomal integrity were recorded in neat semen followed by diluted and frozenthawed semen in both the studies. The proportion of slow progressive sperm were the highest $(p<0.01)$ in the neat and diluted semen followed by rapid and nonprogressively motile, while a reverse pattern was observed in the frozen-thawed semen, but the correlations, as we examined, have not been documented by them.

The present study showed that the hypoosmotic swelling reactive sperm, total motile sperm, curvilinear velocity, linearity, wobbling, beat-cross frequency, amplitude of lateral head displacement, and dancing mean of fresh sperm had significant positive or negative correlations with post-thaw CASA parameters in Gir, Surti and Murrah all three breeds $(\mathrm{r}=0.41$ to 0.68$)$. Thus, CASA analysis of fresh semen for above traits can be used to predict the post-thawed sperm kinematics of bovine semen.

\section{Acknowledgement}

We thank the Dean of the College and authorities of Anand Agricultural University, Anand for the facilities provided for this work.

\section{References}

Amann, R.P. and Waberski, D. 2014. Computer-assisted sperm analysis (CASA): capabilities and potential developments. Theriogenology, 81, 517.

Anand, M. and Yadav, S. 2016. Assessment of motion and kinematic characteristics of frozen-thawed Sirohi goat semen using computer-assisted semen analysis, Veterinary World, 9(2), 203-206.

Anderson, M., Hellman, T., Holmström, B.G., and Jokinen, L. 1992. Computerized and subjective assessments of post-thaw motility of semen from Finnish Ayrshire AI bulls in relation to nonreturn rates. Acta. Vet. Scand., 33(1), 89-93.

Budworth, P.R., Amann, R.P. and Chapman, P.L. 1988. Relationships between computerized measurements of motion of frozen-thawed bull spermatozoa and fertility. J. Androl., 9: 41-54.

Chaudhari, D.V., Dhami, A.J. and Patel, A.C. 2014. Norms and interrelationships of quality attributes of fresh, refrigerated and cryopreserved buffalo semen. Indian J. Field Vets., 10(2), 93-99.

Chaudhary, P.J., Dhami, A.J., Chaudhari, D.V. and Parmar, S.C. 2017. Freezability of cattle and buffalo semen and association of fresh and frozenthawed sperm quality parameters. Intl. J. Curr. Microbiol. \& Appl. Sci., 6(12), 1445-1454.

Ferrell, P.B., Presicce, G.A., Brockett, C.C. and Foote, R.H. 1998. Quantification of bull sperm characteristics measured by computer-assisted sperm analysis (CASA) and the relationship to fertility. Theriogenology, 49, 871-879.

Jayendran, R.S., Van der Ven, H.H., PerezPelaez, M., Crabo, B.G.M and Zaneveld, L.J.D. 1984. Development of an assay to assess the functional integrity of the human sperm membrane and its relationship to other semen characteristics. J. Reprod. Fertil., 70, 219-228.

Kathiravan, P., Kalatharan, J., Edwin, M.J. and Veerapandian, C. 2008. Computer automated motion analysis of crossbred bull spermatozoa and its relationship with in vitro fertility in zona-free 
hamster oocytes: Anim. Reprod. Sci., 104, 9-17.

Kumar, S., Kumar, A., Singh, A.K., Honparkhe, M., Singh, P. and Malhotra, P. 2018. Improvement in post-thaw semen quality by minimizing the lipid peroxidation following herbal treatment in sub fertile buffalo bulls. The Pharma Innovation, 7(5-D), 240.

Lodhi, L.A., Zubair, M., Qureshi, Z.I., Ahmad, I. and Jamil, H. 2008. Correlation between hypo-osmotic swelling test and various conventional semen evaluation parameters in fresh Nili-Ravi buffalo and Sahiwal cow bull semen. Pakistan Vet. J., 28, 186-188.

Mandal, D.K., Nagpaul, P.K. and Gupta, A.K. 2003. Motion characteristics of Murrah buffalo bull spermatozoa in various seasons and its relationship with functional integrity of the plasmallema. Theriogenology, 60, 349-358.

Patel, J.B. and Dhami, A.J. 2013. Computer assisted sperm analysis of fresh and frozen-thawed HF x Kankrej (F1) bulls' semen and their interrelationship. Indian J. Anim. Res., 47, 315-320.

Patel, J.B. and Dhami, A.J. 2016. Computer assisted sperm analysis of fresh and frozen-thawed buffalo semen and their interrelationship. Indian J. Anim. Res., 50, 8-13.

Rana, C.M. and Dhami, A.J. 2003. Interrelationship among various spermatozoal traits of fresh, postthawed and refrigerated semen of Gir and Jafarabadi bulls following sephadex filtration. Indian Vet. Med. J., 27, 3236.

Shelke, V.B. and Dhami, A.J. 2001. Comparative evaluation of physicomorpho-logical attributes and freezability of semen of Gir cattle (Bos indicus) and Jafarabadi buffalo (Bubalus bubalis) bulls. Indian J. Anim. Sci., 71, 319-324.

Snedecor, G.W. and Cochran, W.G. 1994. Statistical Methods. $14^{\text {th }}$ edn. Oxford and IBH Publishing House, New Delhi, India.

Tiwari, M., Prasad, R.B. and Gupta, H.P. 2009. Physico-morphology and in-vitro fertility of semen/spermatozoa of Tarai buffalo semen. Indian J. Anim. Physiol., $1,11-14$.

Verstegen, J., Iguer-Ouada, M. and Onclin, K. 2002. Computer assisted semen analyzers in andrology research and veterinary practice. Theriogenology, 57, 149-179.

\section{How to cite this article:}

Pathak, P.K., A.J. Dhami and Chaudhari, D.V. 2018. Correlations of Fresh Sperm Quality and Kinematic Attributes to Those of Post-Thawed Sperms of Bulls Assessed by CASA. Int.J.Curr.Microbiol.App.Sci. 7(09): 2606-2615. doi: https://doi.org/10.20546/ijcmas.2018.709.324 